\title{
Study on drainage layer strategy for improving performance of glass fibrous coalescing filter
}

\author{
chengwei $\mathrm{xu}^{1}$, chenglong $\mathrm{xiao}^{1}$, Yan $\mathrm{yu}^{1}$, and xiaodong $\mathrm{si}^{1}$
}

${ }^{1}$ Affiliation not available

November 19, 2020

\begin{abstract}
The drainage layer strategy is a common method for improving filtration performance of coalescing filter. In this study, using the commercial glass fibrous filters, the influence of sub-high efficiency drainage layers on high efficiency coalescing filters were investigated experimentally. The efficiency of coalescing filter slight increases, whereas the total wet pressure drop reduces 0.32 $\mathrm{kPa}$ after assembling drainage layer. In addition, the influence of pore size, thickness and wettability on performance were evaluated. While the pore size of drainage layer decrease, the wet pressure drop reduces and quality factor increase. Likewise, the thickness of drainage layer also has positive effect on filtration performance. By contrast, the wettability has a weak affect on the filtration performance. As different coalescing filter with the same drainage layer, the improvement in the filtration performance increase with the decrease of pore size difference between the coalescing and drainage layers.
\end{abstract}

\section{Hosted file}

manuscript.pdf available at https://authorea.com/users/376982/articles/493823-study-ondrainage-layer-strategy-for-improving-performance-of-glass-fibrous-coalescing-filter 